\title{
Discoid lupus erythematosus: when a superficial injury is a red herring of underlying disease
}

\author{
Emily Senderey, Shamik Patel
}

Internal Medicine, Florida Atlantic University, Fort Lauderdale, Florida, USA

\section{Correspondence to} Emily Senderey, esender2@health.fau.edu

Accepted 4 October 2017

\section{DESCRIPTION}

A 64-year-old woman with no dermatological history presents with a rash over her left eyebrow for the past 3 months with associated itching. The patient also states she has a bruise on her scalp from an accidental injury 1 year previously that continues to be sore. She was previously seen by her primary care physician after her injury, who dismissed the lesion as a haematoma.

On physical examination, the patient has a single erythematous papule on the left eyebrow with grey dot granules and mild telangiectasia (figure 1). On examination of the right frontal scalp, the patient has a well-demarcated, erythematous lesion with induration and overlaying alopecia (figure 2). Remaining dermatological examination is unremarkable.

A punch biopsy of both lesions was taken. Pathology showed scarring alopecia of the scalp associated with cutaneous lupus erythematosus and corresponding results for the eyebrow lesion.

With suspicions of discoid lupus erythematosus confirmed by biopsy, proper management of the patient could commence. The patient was referred to rheumatology where workup for systemic lupus erythematosus was negative. The patient was then prescribed clobetasol propionate $0.05 \%$ foam and hydrocortisone $2.5 \%$ cream for topical application.

On follow-up dermatology visit 21 days after initiation of treatment, the patient reports complete resolution of the lesion on the left eyebrow and decreased irritation and redness of the scalp lesion.

Contributors All persons who meet authorship criteria are listed as authors, and all authors certify that they have participated sufficiently in the work to take public responsibility for the content.

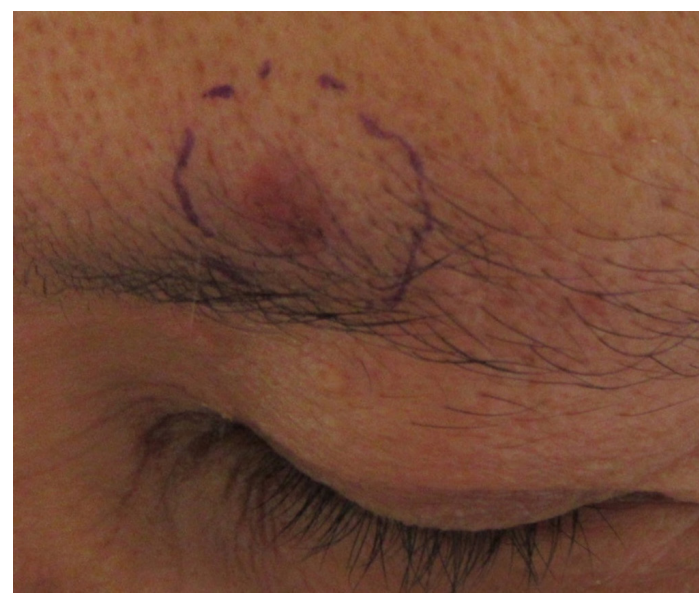

Figure 1 Image of left eyebrow; note lesion encircled by blue ink.

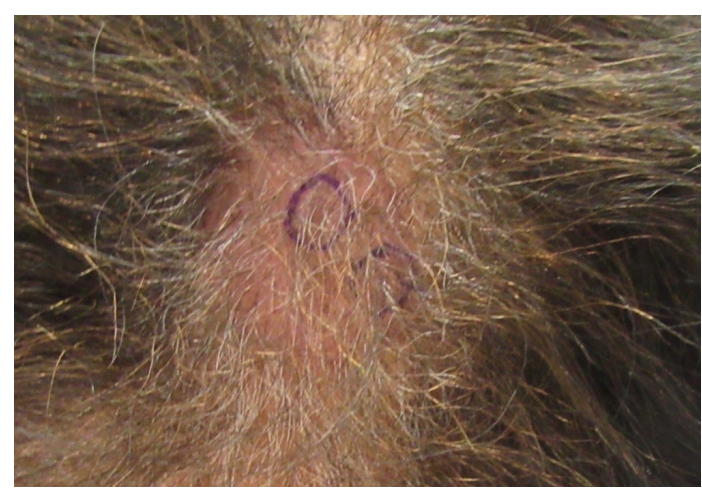

Figure 2 Right frontal scalp; note multiple lesions encircled by blue ink and overlaying alopecia.

Learning points

Injury to the skin can provoke the development of discoid lupus erythematosus activity due to the inflammatory state, known as the Koebner phenomenon. ${ }^{1}$ It is important to consider autoimmune disease in the differential of non-healing injuries.

- The diagnosis of discoid lupus erythematosus is challenging when based on clinical findings alone. For example, lesions are typically neither painful nor pruritic. ${ }^{2}$ Referral to a dermatologist is usually necessary.

- Many patients will have cutaneous lupus erythematosus without signs or symptoms to meet criteria for systemic lupus. ${ }^{3}$ The lack of systemic findings does not rule out cutaneous lupus. It is important to identify cutaneous lupus early to prevent the development of alopecia and counsel patients on the possibility of developing systemic lupus erythematosus.

Furthermore, each author certifies that this material or similar material has not been and will not be submitted to or published in any other publication before its appearance in the BMJ case reports. ES is involved in the the conception and design, literature research, data interpretation, drafting the article, critical revisions and final approval of the version to be published. SP is involved in the design data collection, drafting of the article, critical revisions and final approval of the version to be published.

Competing interests None declared.

Patient consent Obtained.

Provenance and peer review Not commissioned; externally peer reviewed.

(C) BMJ Publishing Group Ltd (unless otherwise stated in the text of the article) 2017. All rights reserved. No commercial use is permitted unless otherwise expressly granted. 


\section{REFERENCES}

1 Ueki H. Koebner phenomenon in lupus erythematosus with special consideration of clinical findings. Autoimmun Rev 2005;4:219-23.
2. Chee M, Madhok R. Discoid Lupus Erythematosus. SanFrancisco, CA: Epocrates. https:// online.epocrates.com (accessed 4 Nov 2016).

3 Wieczorek IT, Propert KJ, Okawa J, et al. Systemic symptoms in the progression of cutaneous to systemic lupus erythematosus. JAMA Dermatol 2014;150:291-6.

Copyright 2017 BMJ Publishing Group. All rights reserved. For permission to reuse any of this content visit

http://group.bmj.com/group/rights-licensing/permissions.

BMJ Case Report Fellows may re-use this article for personal use and teaching without any further permission.

Become a Fellow of BMJ Case Reports today and you can:

- Submit as many cases as you like

- Enjoy fast sympathetic peer review and rapid publication of accepted articles

Access all the published articles

Re-use any of the published material for personal use and teaching without further permission

For information on Institutional Fellowships contact consortiasales@bmjgroup.com

Visit casereports.bmj.com for more articles like this and to become a Fellow 